\title{
Arte y lenguaje como formas del ser. Deseo, ritmo y desaparición
}

\section{Artículo de reflexión}

\section{Cynthia Ortega Salgado}

Universidad Autónoma del Estado de México, México extvinculacionartes@gmail.com

\section{Juan Mojica Arias}

Universidad Autónoma del Estado de México, México juanmojicaarias@gmail.com

Recibido: 10 de agosto de 2017

Aceptado: 15 de noviembre de 2017

Cómo citar este artículo: Ortega Salgado, Cynthia y Mojica Arias, Juan (2018). Arte y lenguaje como formas de ser. Deseo, ritmo y desaparición. Calle14 revista de investigación en el campo del arte 13 (24) pp. 390-398. DOI: https://doi.org/10.14483/21450706.13533 
ARTE Y LENGUAJF, COMO FURMAS DE SER ARTE Y LENGUAJE COMO FORMAS DE SER ARTE $Y$ LENGUAJE COMO FORMAS DE SER ARTE $Y$ LENGUAJE COMO FORMAS DE SER ARTE Y LENGUAJE COMO FORMAS DE SER arte y lenguaje como form $s$ de ser Arte y len uaje como formas de ser

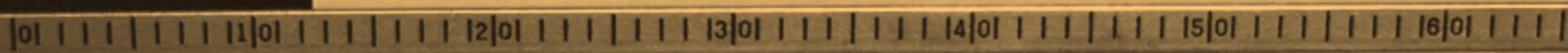

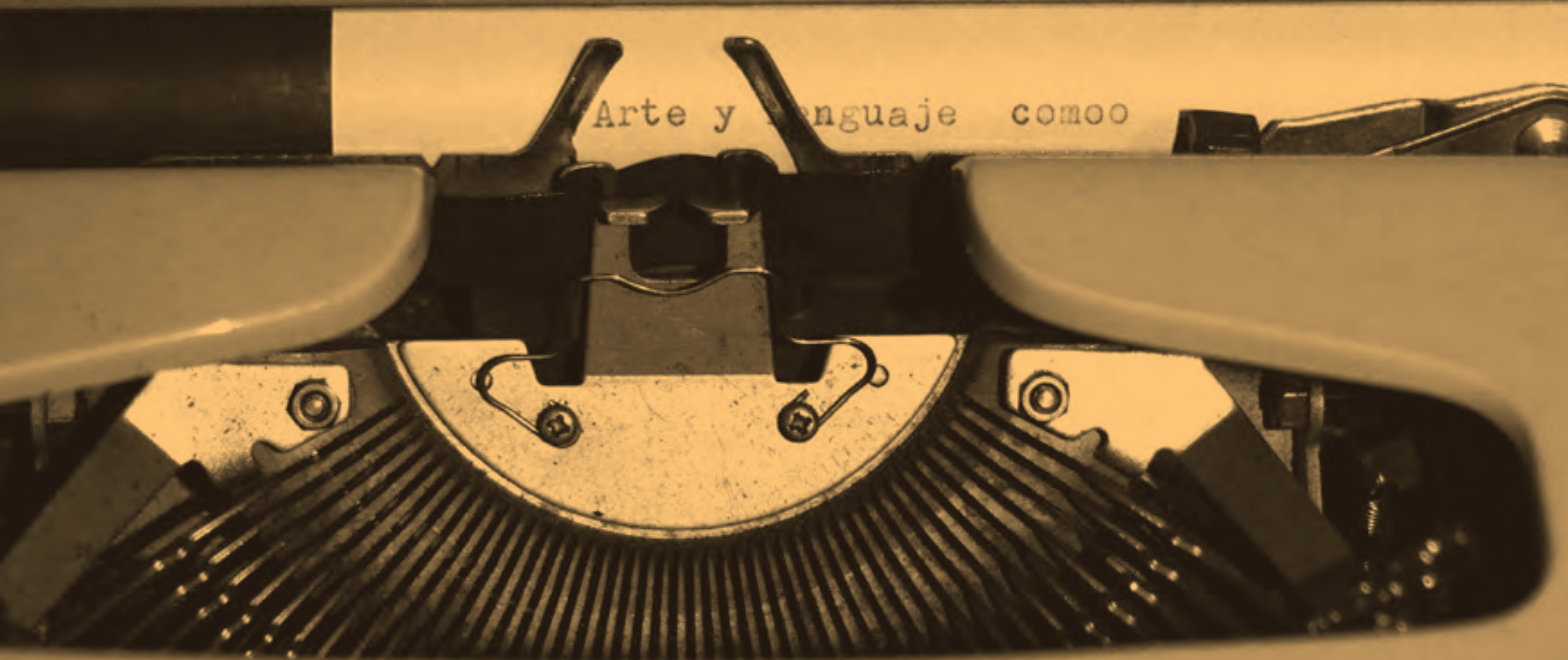

\section{PFHere yetra}




\begin{abstract}
Resumen
Proponemos tres aproximaciones imaginarias que expandan las difíciles relaciones entre arte y lenguaje. La intención es dar lugar a las formas en que el arte construye la realidad. El lenguaje, comúnmente asumido desde su matiz ontológico, podría pensarla en términos de inmanencia, de gramaticalidad. Sin embargo, ¿cuáles serían estas estructuras desde el arte? Este artículo plantea la imagen como desaparición, como ritmo y como deseo para explorar el lenguaje de lo menor, de la sensación y de lo no dicho.
\end{abstract}

\title{
Palabras claves
}

Arte, imagen, lenguaje, ontología.

\section{Art and Language as forms of being. Desire, rhythm and disappearance}

\begin{abstract}
We propose three imaginary approaches to expand the difficult relations between art and language. The intention is to set a place for the forms in which art builds reality. Language, commonly assumed from its ontological nuance, could think reality in terms of immanence and grammaticality. But, what would these structures look like from art? This paper poses image as disappearance, as rhythm and as desire in order to explore the language of the minor, of the sensation and of that what goes unsaid.
\end{abstract}

\section{Keywords}

Art, image, language, ontology.

\section{L'art et la langue comme formes d'être. Désir, rythme et disparition}

\section{Résumé}

Nous proposons trois approches imaginaires qui élargissent les relations difficiles entre l'art et le langage. L'intention est de donner naissance à les manières avec lesquelles l'art construit la réalité. Le langage, communément assumé depuis sa nuance ontologique, pourrait penser en termes d'immanence, de grammaticalité. Cependant, quelles seraient ces structures à partir de l'art ? Cet article présente l'image comme disparition, comme rythme et comme désir afin d'explorer le langage du moindre, de la sensation et du non-dit.

\section{Mots clés}

Art, image, langage, ontologie.

Arte e linguagem como formas de ser. Desejo, ritmo e desaparecimento

\section{Resumo}

Propomos três abordagens imaginárias que expandem as difíceis relações entre arte e linguagem. A intenção é dar origem aos modos pelos quais a arte constrói a realidade. A linguagem, comumente assumida a partir de suo matiz ontológico, poderia ser pensada em termos de imanência, de gramaticalidade. No entanto, quais seriam essas estruturas da arte? Este artigo apresenta a imagem como um desaparecimento, como um ritmo e como um desejo de explorar a linguagem do menor, da sensação e do não dito.

\section{Palavras chaves}

Arte, imagem, linguagem, ontologia. 


\section{Maillallachiska:}

Churakimi tukuikunamanda iuarispa allilla kawangapa maipim kausanchi imam iuanchi aidanchingapa tukuikunata kawachispa imasam ka chasallata munanchi kawachinga ima nukanchi munaska.

Rimangapa Ministidukuna:

Rurai, kawachii, parlaii, ontología. 


\section{Lenguaje como posibilidad amplia de enunciación}

A menudo el lenguaje es pensado como una estructura totalizante en cuyo uso se finca el conocimiento. Esta propuesta duda de ese lugar, entonces ¿desde dónde pensarlo? De acuerdo a María Antonia González Valerio, la diferencia fundamental de su posición, en cuanto a tradiciones filosóficas, se resume en "analíticos vs continentales, [...] epistemología para unos, ontología para otros" (González, 2006, p. 1), es decir, preguntar por el conocimiento desde el lenguaje o ubicar a este como conocimiento. Por un lado, el planteamiento de que la realidad se conoce a través de los elementos que la componen (unidades que viven fuera del sujeto) y por otro, que la realidad se crea mediante abarcadoras formas de enunciación (sujeto e imaginación).

Se sospecha del lenguaje cuya mezcla y combinación conformaría la producción de pensamiento de todos los individuos. Su comprensión se amplía si lo pensamos como un tipo de comunicación extragramatical, en lugar de una producción específica contenida en palabras o libros. En él también existen las relaciones no nombradas, las intuiciones y las imágenes. El lenguaje es incluso en lo no enunciable, en los pensamientos y confines de las experiencias desde la llamada primeridad. Esta se conoce en los hombres por medio del cuerpo y la gestualidad, que desarrollados miles de años antes que la palabra, son formas de escritura $y$, por tanto, de lenguaje. Disentimos de este como dispositivo y lo afirmamos como estrategia de comunicación extralingüística, capaz de unir lo dicho y lo no dicho. Según González Valerio, el lenguaje es capaz de nombrar "lo que somos, lo que hemos sido y lo que todavía no somos, porque el lenguaje nos dice y en él hemos de buscar decirnos" (González, 2006, p. 11).

\section{Arte y lenguaje}

Basada en el principio ontológico gadameriano, que comprende al ser como lenguaje, la autora González Valerio menciona que: "[...] aquello que sea el ser solo se nos da y se re-presenta como lenguaje, porque todo lo que existe, existe dentro de un horizonte humano y ese horizonte es lingüístico, porque tratamos con la realidad en términos lingüísticos" (González, 2006, p. 4). En ese sentido: "[...] lo que existe, existe sólo "para nosotros" (como decía Hegel, el en sí de la cosa es en sí para nosotros)" (5). Por lo tanto, pensar la realidad implica detenerse en el para nosotros, es decir, en cómo la imagen y el arte adquieren una condición particular de enunciación que parece construir y re-construir el horizonte del lenguaje, y por lo mismo, el horizonte de lo humano. ¿De qué manera el arte se relaciona con el lenguaje? ¿Cuáles son los códigos y las gramáticas que expanden el lenguaje? Y ¿En qué sentidos el arte amplía una realidad que, en principio, entendemos como lingüística?

Asumir un vínculo ontológico con el lenguaje nos lleva a preguntarnos por 'la fuerza creadora de la palabra' que parece manifestarse en la imagen, es decir, en qué sentidos esta rebasa su carácter representativo, de imitación o de copia de un mundo que existe con independencia de la conciencia humana. Y así abrir la imagen a los modos en que esta se da en el lenguaje y, en ese sentido, "[...] lanzar la pregunta ontológica desde la estética, desde la experiencia sensible, directa y reflexiva con la existencia, con la escritura, con la imagen, con el arte." (González, 2006, p. 11). Lo anterior invita a pensar los regímenes de representación y significado desde su contradicción con los paradigmas disciplinarios definidos, con la imagen que se contiene en la técnica y que apuesta por el pensamiento desde las influencias y géneros que heredan los objetos catalogados como 'arte'.

Propuestas como el "giro pictorial" (Mitchell, 2009) y el consecuente "giro icónico" (Moxey, 2009), reconocen estas demandas ontológicas e invitan a asumir un entendimiento ampliado de las imágenes y del lenguaje que rompe los límites semióticos y plantea campos de enunciación imaginaria fuera de la mímesis platónica como paradigma representacional y epistémico. De esta forma, se sientan las bases para pensar un tipo de ontologización de la imagen y del arte como lugares donde transita el lenguaje. Lugares que rebasan la norma y la tradición dogmática del arte y que nos gustaría situar en su posibilidad más débil: los procesos anómalos (Sauvagnargues, 2004) y de minorización (Deleuze y Guattari, 1978). Estos permiten plantear la diferencia y los paisajes paradójicos del pensamiento como lugar de apertura para el lenguaje.

Seguir el paso de lo anómalo en el arte inicia sus posibilidades lingüísticas, dado que "[...] el análisis de lo normal y lo anómalo aclara el estatuto de lo invariante en lingüística y opone a los defensores de una gramaticalidad constituida (uso normal, norma mayor), como Chomsky, a aquellos que, como Lamov, consideran que la lengua no es una estructura dada sino una variación anómala" (Sauvagnargues, 2004, p. 62). Un cuerpo sin órganos ${ }^{1}$ del organismo capitalista del arte, que plantea

$1 \quad$ Ver Deleuze y Guattari (2010) 
ontologías móviles desde la apertura y la incertidumbre, el pensamiento paradójico del lenguaje y los entendimientos menores de la lengua como lugares de apertura y enunciación.

Entre lo normal y lo anómalo de la imagen, entre lo mayor como la norma constituida culturalmente y la desterritorialización de la lengua, Kafka² aparece como una muestra de lo menor en la literatura que se margina de la cronología, del lenguaje dominante y la representación. En otras palabras, “La creación literaria es llamada $<<$ menor $>>$ en el sentido de que mina y socava las condiciones sociales de la norma mayor. [...] un ejercicio de minoridad, de minorización, que desequilibra las normas" (Sauvagnargues, 2004, pp. 59-60), y de esta forma genera nuevos territorios representacionales.

El arte, desde un entendimiento menor y anómalo, enfatiza los fenómenos contingentes y cambiantes del lenguaje, explorando zonas de indiscernibilidad, el 'centro frágil e incierto' en el que acontece la existencia. ¿Cuáles podrían ser algunas gramáticas particulares del arte? ¿Cuáles sus posibilidades de enunciación? Se proponen tres: las latencias que brillan en la imagen como desaparición, los agenciamientos propios de la imagen como ritmo y los acoplamientos hechos desde la imagen como deseo.

\section{Desaparición}

Es sencillo averiguar cómo nace una imagen, su creación o su circunstancia, pero ¿se podría rastrear su desaparición? Primera cuestión ¿podría una imagen desaparecer? ¿cuál sería la naturaleza de la imagen que desaparece? Jean Baudrillard decía que “Cuando en lugar de destruir algo se logra borrar su origen y su fin, desaparece..." (Baudrillard, 1989, p. 82). Evaporar el inicio y suprimir el fin de una imagen, desliarla de todo principio y evitar cualquier conservación o extensión. La imagen que desaparece es una que ha anulado sus huellas, que se ha consumido.

La desaparición es un estado impreciso y flotante, la cosa, la persona o la imagen no está "físicamente muerta" sino que "Resplandece en una suerte de estado de gracia" (Baudrillard, 1989, p. 82). Tanto los

2 Personaje paradigmático utilizado por Deleuze \& Guattari (1978) para plantear la desterritorialización de la lengua como el lugar de lo menor en la literatura. desaparecidos ${ }^{3}$ como el gato en la caja imaginaria de Erwin Schrödinger ${ }^{4}$, están expuestos al mismo tiempo a dos eventualidades: vida y muerte, superposición de estados. Hasta que no se encuentren los restos de los primeros, no se sabe si están vivos o no, y si se abriera la caja del animal para averiguar, se alteraría todo el sistema y la doble condición sería perturbada. Lo importante de la maquinación de Schrödinger es concebir dos estadios de indeterminación a la vez. Si el gato vive o perece la paradoja termina, "Porque lo que muere es aniquilado en el tiempo lineal, pero lo que desaparece pasa al estado de constelación" (Baudrillard, 1989, p. 82).

Posiblemente la imagen tiene dos formas de ser constelación: la desaparición inherente a su naturaleza insustancial, es decir, la configuración que adquiere bajo nuestras membranas oculares y la desaparición creada por uso o propagación excesiva ${ }^{5}$. Lo que nos compete es la primera. ¿Qué sucede con una imagen al ser captada con la vista y después retenida? La potencia del principio se desvanece para tomar otra forma; “...la reminiscencia es una búsqueda en este fantasma... algunos se desasosiegan cuando no consiguen recordar a pesar de su intensa aplicación mental..." (Agamben, 2010 , p. 14). Se cierra los ojos y se ve la imagen en su forma interior, en su latencia. Al respecto Giorgio Agamben refiere a un tratado de danza ${ }^{6}$ cuyos elementos fundamentales son: "...medida, memoria, agilidad, manera, cálculo del espacio y "fantasmata"" (Agamben, 2010, p. 13). Este último y misterioso elemento es el que cabe en dos momentos: mirar y contener; entre ver lo que Agamben llama "la cabeza de Medusa"7, es decir, quedar petrificado y contener en movimiento el siguiente paso. Lo que hay en el cuerpo y la mente del bailarín es un espacio, el espacio de una imagen que abraza dos instantes enfrentados en un mismo sitio. Esta figuración “...(phantasma) ...es una afección, un pathos de la sensación o del pensamiento" (Agamben, 2010, p. 14). El bailarín crea en su cuerpo una imagen que padece, una pasión que lo hace inventar un pretexto entre mirada y contención.

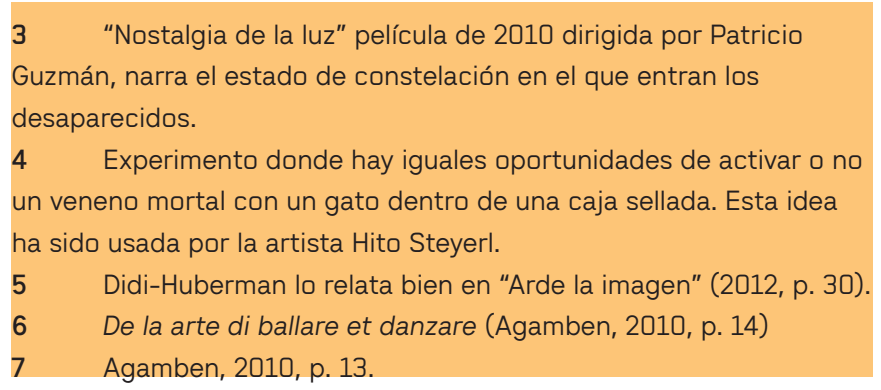


Una afección es una "impresión que hace algo en otra cosa, causando en ella alteración o mudanza"8. Precisamente, lo que hace una imagen es mudar la realidad. Al ser engullida por los sentidos desaparece y se rehace, para luego desaparecer de nuevo ${ }^{9}$. Por más que nos empecinemos en fijarla, su estabilidad es ilusoria y evanescente, como el sutil aroma de alguien que se ha ido; "Las imágenes están vivas, mas, hechas como están de tiempo y de memoria, su vida es ya y siempre Nachleben, supervivencia, amenazada sin cesar y en trance de asumir una forma espectral" (Agamben, 2010, p. 23). En ese tránsito las imágenes se cargan de tiempo hasta explotar y asumir su ser fantasmático.

En otro ejemplo muy pertinente, un sobreviviente del Sonderkommando de Auschwitz afirmó haber enterrado una cámara fotográfica con imágenes de los crematorios ${ }^{10}$, el artefacto nunca fue encontrado. ¿A quién pertenecen las imágenes grabadas en el rollo? ¿se recrea la imagen como impresión en los que conocen la historia? Aunque la cámara hubiese sido hallada, la naturaleza de las imágenes permanecería en pausa, escondidas en la oscuridad del encierro, no hacen más que palpitar. Como el gato en la caja de Schrödinger o los hombres y mujeres desaparecidos, las imágenes están atrapadas en la penumbra de su doble estado.

\section{Ritmo}

Un niño en la oscuridad, presa del miedo, se tranquiliza canturreando. Camina, camina y se para de acuerdo con su canción. Perdido, se cobija como puede o se orienta a duras penas con su cancioncilla [...] salta del caos a un principio de orden del caos [...]. Siempre hay una sonoridad en el hilo de Ariadna. O bien en el canto de Orfeo. (Deleuze y Guattari, 2010, p. 318).

“[...] el medio no territorializado es una abstracción que carece de existencia para cualquier viviente" (Sauvagnargues, 2004, p. 149)

Del caos (Deleuze y Guattari, 2010) surgen medios y ritmos como principios de orden; territorios significantes que seccionan y configuran el mundo del viviente. Territorios, relaciones, órdenes y agenciamientos

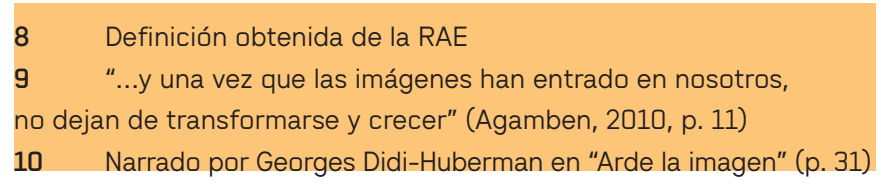

ritmados, en términos de Deleuze y Guattari (2010:317358), ritornelos que devienen expresivos: “[...] hay ritmo desde el momento en que hay paso transcodificado de un medio a otro, comunicación de medios, coordinación de espacios-tiempos heterogéneos" (Deleuze y Guattari, 2010, p. 320). Medios y ritmos significantes, cambiantes, que se repiten y transforman dentro de realidades habitadas por personajes rítmicos y paisajes melódicos con diferentes cualidades tonales. Territorios expresivos, medios que entran en un juego de transcodificación en los diferentes acoplamientos en los que acontece la existencia. Es por eso que: “[...] la canción nunca termina, se prolonga indefinidamente transformándose a sí misma; produce siempre nuevas notas en la relación activa que los vivientes entablan entre sí y con sus mundos." (Heredia, 2011, p. 77).

Los lugares paradigmáticos utilizados por Deleuze y Guattari (2010, pp. 15-321) para plantear relaciones entre heterogéneos y juegos de transcodificación, son los ejemplos de la relación araña-mosca y avispaorquídea. Donde se hace evidente cómo ciertos códigos genéticos con línea evolutiva diferente se implican de manera recíproca: “[...] melodías que se harían contrapunto, la una sirviendo de motivo a la otra y recíprocamente" (p. 321), ontologías de coordinación, afinidades inmanentes que los animales crean con el mundo. Lo que el etólogo J. Von Uexküll (1864-1944) planteó como el modelo musical de la naturaleza (Heredia, 2011, p. 71), la sonoridad que construye territorios.

Esto nos permite pensar en el umbral animal del arte (Sauvagnargues, 2004) como aquello que comprende los acoplamientos territoriales, que los produce a través de ritmos y melodías expresivas. Si pensamos que "el arte es una territorialización expresiva." (p. 150), inmanente y vital, este sostendría entonces una relación privilegiada con lo animal en la construcción de geo-grafías, en el sentido que abre la realidad a diferentes tipos de acoplamientos simbólicos, que poseen diferentes expresividades y se construyen a partir de imágenes rítmicas: "[...] diríase que la araña tiene una mosca en la cabeza, un "motivo" de mosca, un "ritornelo" de mosca" (Deleuze y Guattari, 2010, p. 321). De manera que la imagen artística transita la re-presentación del mundo y del lenguaje, ésa es su característica fundamental, ya que los ritmos expresivos y sensibles con los que se relaciona con la realidad, son los lugares donde se construyen los agenciamientos propios del territorio y del lenguaje, planteando escenarios de re-conocimiento. 


\section{Deseo}

El pensamiento occidental acarrea una definición complicada del deseo. En Pitágoras, Platón y Sócrates se desea sólo lo que no se posee, lo que se aspira tener, que en el caso de la filosofía es el conocimiento o la verdad; es menester salir de mí mismo para iniciar la búsqueda de aquello de que carezco. Contrario a la falta ${ }^{11}$, continuamos la idea deleuziana de que el deseo comprende más bien una suma de intensidades ${ }^{12} 12$. El devenir del sujeto es inagotable por la potencia latente de todos sus acoplamientos. El "cuerpo sin órganos" es un ejemplo por excelencia del organismo deseante, pues es "... un Colectivo (agenciando elementos, cosas, vegetales, animales, herramientas, hombres, potencias, fragmentos de todo eso..." (Deleuze y Guattari, 2010, p. 166).

Si nos asumimos como cuerpos con fronteras lábiles, es decir, haciendo relaciones contra texturas, colores, sensaciones, temperaturas, seres, etcétera, existen posibilidades infinitas para expandir nuestras capacidades, por tanto, seremos al tamaño y a las competencias de nuestros agenciamientos. El deseo descrito no carece de nada porque es uno en posibilidad, no renuncia a sus aptitudes, vive por exceso, es precisamente su desbocamiento lo que impide darle forma. No hay restos o insatisfacción, pues "...se revela como lo que es, conexión..., conjunción de flujos, continuum de intensidades" (Deleuze y Guattari, 2010, p. 166).

Clément Rosset también propone un deseo que no se basa en la fantasía o en la ausencia, sino en lo real y sus entrelazamientos, como energías que lo alimentan y realimentan. "Lejos de despreciar lo real, el deseo, al contrario, lo aprecia a tal punto que retarda el instante de consumirlo hasta el momento ilusorio en que estaría en estado de gozar de él enteramente..." (Rosset, 2007, p. 61). No se trata de un debate inútil entre el deseo construido a partir de la ausencia o la presencia, sino que ellos "...designan dos experiencias radicalmente diferentes: ...un deseo paradójicamente sin objeto...; por la otra, la experiencia del deseo propiamente dicho, cuyo único y permanente objeto es lo real" (Rosset, 2007, p. 62).

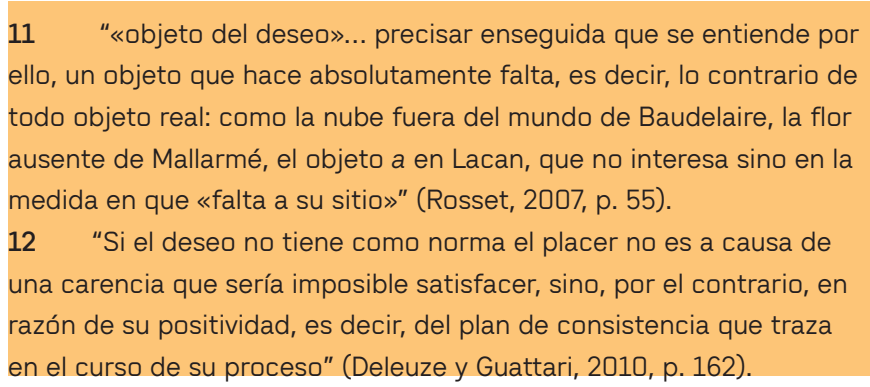

¿Cómo sería la imagen pensada desde la abundancia de deseo? Se trataría de una imagen flujo, que cambiara su configuración, que se presentara siempre distinta y cuya significación se transformara en el tiempo. Cada imagen de acuerdo a la época en la que fue realizada, posee una única naturaleza. Regis Debray distingue tres etapas en las que el pensamiento y el modo de ser de la imagen es diferente: logosfera, grafosfera y videosfera. Según el autor, a la primera corresponde el ídolo, a la segunda el arte y a la tercera lo visual. Aunque las tres han sido presas del deseo del autor y el espectador, se podría enunciar que lo visual "está en rotación constante, ritmo puro, obsesionado con la velocidad" (Debray, 1994, p. 177) y que es en este régimen donde la imagen pensada como flujo encuentra sus mayores desplazamientos.

La imagen como deseo realiza acoplamientos con todo lo que en ella se refleja, actúa como un espejo que manifiesta lo que el sujeto posee en sí mismo, pues “... es engendrada a cada instante según el movimiento o la presencia de quien la contempla: "como la luz es creada siempre de nuevo según la presencia de lo alumbrante, así decimos de la imagen en el espejo que ella se genera cada vez según la presencia de quien mira". El ser de las imágenes es una continua generación (semper nova generatur)" (Agamben, 2013, p. 72). El teórico italiano hace una reflexión importante, si las imágenes fueran simples sustancias se moverían junto al espejo que las revela, si fueran cuerpos se superpondrían al propio reflejo del espejo, pero no son ni unas ni otros "sino un accidente que no está en el espejo como en un lugar, sino como en un sujeto (quod est in speculo ut in subiecto)" (Agamben, 2013, p. 71). Es el sujeto el topos donde la imagen se juega, donde corren los "...flujos de intensidad..." ${ }^{13}$ y las continuidades. Es a través de las imágenes que soñamos y fabricamos, que el deseo se expande y propaga, pues se hace excesivo en lo real, como el de Don Quijote ${ }^{14}$. El deseo está en la imagen que se construye y que decanta, a su vez, a quien la piensa.

\section{A modo de cierre}

Comprendemos los riesgos que implica reflexionar el arte desde terrenos que tradicionalmente han pertenecido a la filosofía. No obstante, encontramos inevitable aproximarnos en un juego que busca desplazar y matizar

\footnotetext{
13 Deleuze y Guattari, 2010, p. 166.

14 "que retarda el instante de consumirlo hasta el momento ilusorio en que estaría en estado de gozar de él enteramente" (Rosset, 2007, p. 61).
} 
dogmas que no nos permiten pensar. El arte, más allá de ser un resultado evidente y material de diferentes tipos de sensibilidad, es el camino propuesto para atender las complejidades en las que se produce la existencia.

Es por ello que basamos la proposición sobre espacios que no nos pertenecen, aunque esto nos haga sentir incómodos y torpes, ya que cuando la filosofía se convierte en ontología, formula múltiples preguntas en dirección al arte y la estética, y se comparten inquietudes por lo todavía no dicho, por las aperturas que el arte, a través de su experiencia directa y sensible del mundo, genera.

Encontramos, en los límites del pensamiento filosófico un lugar desde donde razonar. Indagamos en las posibilidades que el arte abre desde el lenguaje para describir aquellos escenarios donde la ontología puede ser una forma de experiencia en la práctica artística. Para lograr este cometido se debe expandir el lenguaje desde su práctica, por lo que acudimos a planteamientos que posicionan la lengua como un proceso y una potencia: en ideas como la minorización, la enajenación o la anomalía. Este texto plantea tres caminos, si se quiere gramáticas o disposiciones particulares de existencia, desde donde se pueda significar un conocimiento que parece escurrirse entre los dedos: el arte como pensamiento.

De este modo, deseo, ritmo y desaparición, se presenta como una aproximación a la máquina imaginaria que produce la realidad. El deseo hace énfasis en la mirada, el ritmo en la escucha y la desaparición en la vibración. El deseo en la imagen sería una inagotable pulsión por mirar, algo que siempre representará una suma en el sujeto, un acoplamiento desde lo que aparece en el espejo. El ritmo implica un sujeto que escucha y se pierde en la sonoridad del hilo de Ariadna, en su extraordinaria instrumentación; finalmente, la desaparición, se presenta como condición doble y paradigmática donde no se sabe si las cosas están o no, por lo tanto, se presiente sólo sutilmente, a manera de vibración.

Se pretende pensar la realidad desde los límites expuestos del lenguaje y la ontología, desde el arte como ontología inmanente. Estos son los sitios que hemos encontrado para "decirnos" de una forma más expandida, asumiendo los riesgos de una escritura visual, pero vehemente.

\section{Referencias}

Agamben, G. (2010). NINFAS. España: Pre-textos. (2013). Profanaciones. Argentina: Adriana Hidalgo editora.

Baudrillard, J. (1989). Cool Memories. Barcelona: Anagrama.

Debray, R. (1994). Vida y muerte de la imagen. Historia de la mirada en occidente. España: Paidós comunicación.

Deleuze, G., y Guattari, F. (1978). Kafka. Por una literatura menor. México: Ediciones Era.

(2010). Mil mesetas. Capitalismo y esquizofrenia

(6a ed.). España: Pre-textos.

Didi-Huberman, G. (2012). Arde la imagen. México: Serieve.

González Valerio, M. A. (2016). Cabe los límites. Escritos sobre filosofía natural desde la ontología estética. México: Herder.

(2006). Gadamer y la ontologización del lenguaje [en línea]. Disponible en: http://www.academia. edu/587248/Gadamer_y_la_ontologización_del_lenguaje

Heredia, J. M. (2011). Etología animal, ontología y biopolítica en Jakob von Uexküll. Filosofia e História da Biologia, 6(1), pp. 69-86.

Mitchell, W. J. T. (2009). Teoría de la imagen (2a ed.). España: Akal.

Moxey, K. (2009). Los estudios visuales y el giro icónico. Estudios visuales, 6. [en línea]. Disponible en: http:// estudiosvisuales.net/revista/index.htm

Núñez García, A. (2010). Gilles Deleuze. La ontología menor: de la política a la estética en Revista de Estudios Sociales, vol., 35, pp. 41-52.

Rosset, C. (2007). El objeto singular. Madrid: Sexto piso.

Sauvagnargues, A. (2006). Deleuze: del animal al arte (1a ed.). Buenos Aires: Amorrortu. 